\title{
Risk of mortality due to COVID-19 and air pollution in Pakistan
}

\author{
Yousaf Ali Khan ${ }^{1,2}$ (D) \\ Received: 14 January 2021 / Accepted: 1 June 2021 / Published online: 7 August 2021 \\ (C) The Author(s), under exclusive licence to Springer-Verlag GmbH Germany, part of Springer Nature 2021
}

\begin{abstract}
The present research aims to investigate the impact of air pollution on the number of mortalities caused by COVID-19 per Pakistani province. To do so, for each independent area of Pakistan, the observed mortality due to COVID-19 has been standardized over the entire population using standard age groups ranging from 0 to 4,5 to 9,10 to $14, \ldots, 65$, and above years, supported by the 2017 state people census. The impact of air pollution and COVID-19 transience among Pakistani areas, Islamabad Capital Territory (ICT), and the Federally Administered Tribal Region (FATA) was analyzed by a multiple-linear regression model, while the broad collection of attributes was observed by the resources of local spatial autocorrelation indicators, including the spatial portion of COVID-19 association. The result indicates that the observed mortality rate is much higher than predicted in certain provinces, namely, the Khyber Pakhtunkhwa and Punjab provinces, and the prevalence of $\mathrm{PM}_{10}$ was independently linked to mortality due to the corona virus. Additionally, the results of the local spatial autocorrelation indicators on the standardized mortality rate and $\mathrm{PM}_{10}$ define a collection of very higher ideologies in the broad range of KPK and the southern part of Punjab province, respectively, with a definite degree of connection between the two distributions in the Khyber Pakhtunkhwa region. In brief, this research seems to find a justification for confirming the existence of a correlation between the possibility of COVID-19 mortality and air pollution, more precisely considering air pollutants (i.e., particulate $\left(\mathrm{PM}_{10}\right)$ and land take-over. To this end, the need to mediate in favor of measures aimed at eliminating emissions in the environment will be reiterated by speeding up current proposals and policies aimed at all causes of atmospheric pollution: urbanization, water and manufacturing, home heating, and transportation.
\end{abstract}

Keywords Corona virus $\cdot \mathrm{PM}_{10} \cdot$ Air pollution $\cdot$ Specific mortality rate $\cdot$ Local indicators of spatial autocorrelation

\section{Introduction}

Air pollution is one of the biggest public quality concerns in the country. According to the International Health Organization, it is attributed that there are 7 million deaths globally each year (WHO Timeline 2020). In Asia, an expected 852,000 people die hastily annually from experience with air contaminants (WHO 2017). Carbon monoxide (CO), particulate matter (i.e., $\mathrm{PM}_{10}$ and $\left.\mathrm{PM} 2.5\right)$, carbon dioxide $\left(\mathrm{CO}_{2}\right)$,

Responsible Editor: Lotfi Aleya

Yousaf Ali Khan

yousaf_hu@yahoo.com

1 Department of Mathematics and Statistics, Hazara University, Mansehra 23010, Pakistan

2 School of Statistics, Jiangxi University of Finance and Economics, Nanchang 330013, China and nitrogen-dependent contaminants are the major air contaminants taken into consideration (e.g. $\mathrm{NO}_{\mathrm{x}}$ ). These compounds are mainly extracted from anthropogenic practices (trafficking, burning, development and industrialization, deforestation and urbanization, population increase, etc.), livestock breeding, and cultivation that modify the composition of the environment (Ghorani-Azam et al. 2016; Rapporto Quali ISPRA 2016). The disability induced by human health fluctuates and relies on the subjectivity of the person, the length of exposure, and the perception of contaminants. Various conditions may be related to revelation; moreover, they vary from judicious and temporary to irreversible figures. Furthermore, sustained experience with toxic intensities above the control restrictions has been shown to trigger a persistent, provocative, and hypermetric syndrome that can contribute to a greater preference for viruses and growth of indicative diseases (Shi et al. 2020; Ma et al. 2020), as well as additional preexisting resistant shifts (Shi et al. 2020; Mazhar et al. 2020). Livelihood in an atmosphere of elevated levels of pollutants 
may often render a human more fragile, and thus it is more likely for infectious agents to develop prolonged respiratory problems. Relatively higher then in 2005 , because the WHO has haggard up strategies defining experience thresholds for the small and lengthy term. In view of this, global monitoring thresholds are not the same and differ from country to country (WHO 2016). The new epidemic of the COVID-19 pandemic SARS-CoV-2 virus has posed several questions in the academic world as to why certain countries have seen larger dissemination of the virus and a higher mortality rate (Lai et al. 2020; Shi et al. 2020; Ma et al. 2020). Pakistan is, in reality, one of the developed countries of Asia, the country most impacted by the corona virus pandemic. The pandemic has acquired a striking character in the world with $45,70,750$ viruses and 10,192 death confirmations as of 31 December 2020, comparatively senior mortally than further Asian countries and several inequalities inside the same national territory as well (Frontera 2020; Mazhar et al. 2020). Numerous suggestions have been placed ahead between the potential details for the principal increase of the virus surrounded by the area, including regarding recent findings showing different associations from the end in view of the geographical and public contact between China and Pakistan (Waris et al. 2020; Anjum et al. 2020). With the trade links connecting Pakistan and China, and the combination of possibilities for the virus to be contacted and imported into our country, knowing why the virus has advanced so suddenly in Pakistan's territory is one of the problems currently boiling the international science discourse. In addition, many other features might be concerned with making easy extent of viruses into society. In reality, a traditionally established occurrence about the spread of extra viruses (i.e., measles) (Peng et al. 2020) indicates that amounts of air effluence and, in particular, particulate matter could serve as a vector within the territory for the spread of the virus. The presence of SARS-CoV-2 RNA in particulate matter, however, was recently demonstrated by Setti et al. (2020a). Consequently, a mixture of air pollution causes, such as pollutants and a broad spectrum of environmental issues in general, may be deemed liable for the objectives within the respiratory territory and declining the at-risk community, thus enhancing their chances of being impacted by respiratory diseases such as COVID-19 (Frontera 2020; D'Alessandro et al. 2020). Khyber Pakhtunkhwa, renowned for its extreme air pollution rate, is home to the most affected areas of Pakistan. This study aims to determine the causal relationship between air pollution and COVID-19 at the regional level from the beginning of these assumptions and a set of current studies showing an advanced case casualty incidence in the Khyber Pakhtunkhwa area (Anjum et al. 2020; Mazhar et al. 2020). More specifically, in relation to the number of deaths caused by corona virus per Pakistani province, the function of air pollution and a collection of ecological variables, preferred from current comments (Waris et al. 2020; Murgante et al. 2020; Dettori et al. 2021), were studied.

Pakistan was partitioned from a managerial position of observation into five districts: Azad Jammu and Kashmir (AJK), Islamabad Capital Territory (ICT), and the Federally Controlled Tribal Area (FATA). Punjab province is divided into 2 independent regions with regional obligations. COVID19 results, as declared by the Ministry of Public Health Services, Government of Pakistan, and as obtained by the Pakistan Statistics Division (PSD), take into account, as of 31 December 2020, the number of overall tainted persons and the numeral of deaths at the provincial level (Pakistan Statistics Division 2020). Data and computational environment knowledge is given in Sect. 2.3, while references to the description and data attainment applicable to environmental variables are defined in Table 1.

The remainder of this research is structured as follows: Sect. 2 presents the methodology and data used in this research, Sect. 3 provides empirical results, while in Sect. 4 the discussion is given. Finally, Section 5 ends this research with useful policy implementations and future research work.

\section{Methodology and data}

\section{Standard mortality rate for COVID-19}

Based on the 2017 national population census, standard mortality from COVID-19 over the entire population age classes (14 groups) ranging from 0 to 4 years to 65 years and above was averaged for each zone of Pakistan. The indirect standardization process initially rendered it possible to predict national real mortality by age category, obtained by dividing the number of COVID-19 deaths by 31 December 2020 and verified by the Ministry of National Health (MNH) by the 14 age groups listed at http://www.covid.gov.pk.

Thus, the number of estimated age groups is based on the 2017 demographic survey for the prespecified age groups. COVID-19 deaths in all provinces, ICT, AJK, and FATA areas were estimated according to the formula:

$a=\sum_{i=1}^{n} Z=\frac{M_{i}}{P_{i}}$

In each observed region, $P_{i}$ is the unique age group population, and $M_{i}$ is the resulting mortality rate for that region's specific age group. The standardized mortality ratio (SMR) was obtained by comparing, in each province, the number of reported COVID-19 deaths with the corresponding number of predicted deaths:

$$
S M R=\frac{D}{a}
$$


Table 1 Description of study variables and sources

\begin{tabular}{lll}
\hline Variables & Description & Sources \\
\hline$N O_{2}$ & Nitrogen dioxide (average yearly value $(\mu \mathrm{g} / \mathrm{mc}))$ & AQICN 2020 \\
$P M_{2.5}$ & Particulate matter $\leq 2.5 \mu \mathrm{m}($ average yearly value $(\mu \mathrm{g} / \mathrm{mc}))$ & AQICN 2020 \\
$P M_{10}$ & Particulate matter $\leq 10 \mu \mathrm{m}($ average yearly value $(\mu \mathrm{g} / \mathrm{mc}))$ & AQICN 2020 \\
PA & Pedestrianized road surface $\left(\mathrm{m}^{2} /\right.$ inhabitant) & ME 2020 \\
$\mathrm{CP}$ & Cycle path & ME 2020 \\
Soil & Soil consumption $($ ha/sqm $)$ & ME 2020 \\
Trees & Number of trees per 100 inhabitants in public spaces & PSB 2020 \\
MC & Number of motorcycles/cars in circulation per 100 inhabitants & PSB 2020 \\
BT & Number of buses/trucks in circulation per 100 inhabitants & ME 2020 \\
UGS & Percentage of urban green spaces & ME 2020 \\
\hline
\end{tabular}

where $D$ is the number of deaths observed for COVID-19; the number of deaths predicted is " $a$." Ninety-five percent confidence intervals ( 95 percent $\mathrm{CI}$ ) were determined for all regions under consideration, following the recommendations of Vandenbroucke (1982).

\section{Pearson correlation}

With the assistance of the Pearson correlation, the relationship between the environmental variables under consideration was evaluated and mathematically expressed as follows:

$r_{x y}=\frac{\sum\left(x_{i}-\bar{x}\right)\left(y_{i}-\bar{y}\right)}{\sqrt{\left(x_{i}-\bar{x}\right)^{2}} \sqrt{\left(y_{i}-\bar{y}\right)^{2}}}$.

\section{Local predictor spatial autocorrelation}

According to Anselin (1995), local predictor spatial autocorrelation (LISA) can be defined as:

A statistic that satisfies the following two conditions is called LISA:

1. LISA for each observation indicates the extent of significant spatial clustering of similar values around that observation.

2. The sum of all LISAs of observations is proportional to a global indicator of spatial correlation.

LISA for a variable $x_{j}$ observed at loction $\mathrm{j}$ as measure $L_{i}$ can be mathematically expressed as

$L_{j}=f\left(x_{j}, x_{k_{j}}\right)$

where $f$ is a function of parameters, and $x_{k_{j}}$ are the observed values in the neighborhood $k_{j}$ of $j$. The values $x$ used in the derivation of the statistic may be the actual observations or some standardization of these to avoid scale dependence of the local indicators. Similar to the exercise often taken for global indicators of spatial association.

\section{Data and computational environment}

The data used in this analysis were extracted from numerous sources. Data related to COVID-19, such as a number of confirmed cases, deaths, active cases, and area recoveries, was collected from the Ministry of National Health Services (MNHS 2020) available at https://www.covid.gov.pk. Realtime air quality monitoring project (AQICN 2020) available at https://www.aqicn.org/country/pakistan/, Ministry of Environment, Government of Pakistan available at http:// www.adaptation-undp.org, and air pollution data were collected from Pakistan Ministry of Climate Change available at http://www.mocc.gov.pk. Results and graphs mentioned in this article were carried out using R-studio computational environment.

\section{Multivariate linear regression model}

With the aid of a multivariate linear regression model, the association between mortality due to COVID-19 and all variables causing air pollution across various regions of Pakistan was well explained. The functional relation between this study's explained variable (SMR) and explanatory variables can be expressed mathematically as follows.

$S M R_{t}=\int\left(P M_{2.5 t}, P M 10_{t}, N O 2_{t}, C P_{t}, U G A_{t}, P A_{t}\right.$, Trees $_{t}$, Soil $\left._{t}, M C_{t}, B T_{t}\right)$

Equation (5) can be rewritten as follows after adding a constant term $\left(\alpha_{0}\right)$ and an error term $\varepsilon_{t}$ wherein $\left(\beta_{k}\right)$ $(k=1,2, . ., 7)$ represent the coefficients of $\mathrm{PM}_{10}, \mathrm{PM}_{2.5}, \mathrm{CP}$, PA, Soil, $\mathrm{NO}_{2}$, Trees, MC, UGA, and BT. 
Table 2 Region wise standardized mortality rate in Pakistan

\begin{tabular}{lllllll}
\hline Provinces & Population & $\begin{array}{l}\text { Area } \\
\left(\mathrm{km}^{2}\right)\end{array}$ & $\begin{array}{l}\text { Population per } \\
\mathrm{km}^{2}\end{array}$ & $\begin{array}{l}\text { Standardized } \\
\text { mortality rate }\end{array}$ & PM $_{10}$ & 95\% CI \\
\hline Sindh & $47,886,051$ & 140,914 & 339.82 & 6.44 & 65.5 & $(7.88,8.02)$ \\
Punjab & $110,012,442$ & 205,345 & 535.744 & 6.58 & 66.13 & $(7.08,7.94)$ \\
Khyber Pakhtunkhwa & $30,523,371$ & 74,521 & 409.59 & 6.71 & 67.5 & $(5.82,6.21)$ \\
ICT & $2,006,572$ & 906 & 2214.75 & 5.44 & 45.5 & $(6.08,6.94)$ \\
Balochastin & $12,344,408$ & 347,190 & 35.5551 & 5.11 & 49.5 & $(6.95,7.47)$ \\
FATA & $5,001,676$ & 27,220 & 183.75 & 3.53 & 36.0 & $(3.57,4.09)$ \\
AJK & $4,045,000$ & 13,297 & 304.20 & 2.33 & 37.0 & $(1.94,2.75)$ \\
GB & $1,249,000$ & 72,971 & 171.30 & 2.11 & 31.0 & $(1.78,2.54)$ \\
\hline
\end{tabular}

$$
\begin{aligned}
S_{M R}= & \alpha_{0}+\beta_{1} P_{2.5 t}+\beta_{2} P M_{10 t}+\beta_{3} N O_{2 t} \\
& +\beta_{4} U G A_{t}+\beta_{5} C P_{t}+\beta_{6} \text { Trees }_{t}+\beta_{7} B T_{t}+\varepsilon_{i t}
\end{aligned}
$$

The findings show that major air toxins such as $\mathrm{PM}_{10}, \mathrm{NO}_{2}$, and $\mathrm{PM}_{2.5}$ and different factors unique to the municipal climate, such as trees, urban population, bike lanes, walking streets, soil, community and town green areas, motorcycles/ cars plus heavy transport, as an independent variable, are defined in detail in Table 1. In a recent analysis (Waris et al. 2020; Murgante et al. 2020; Dettori et al. 2020), these variables were previously analyzed and defined on the foundation of their straight and tortuous connection to the frequency of investigation of air contaminants, evaluated through the explained variable outcome (SMR). In specific, linear regression was approved by means of the interrupted averages from the official measurement systems of the air pollutants collected in this study. At 5\% t-statistics, the significance number was determined. The related $p$ values and 95 percent confidence intervals were determined using R-statistical software for each coefficient and provided in the computation portion of Table 4 .

\section{Empirical results and discussion}

\section{Standardized mortality rates}

Based on official national statistics, the standardized mortality rate (SMR) contrasted the COVID-19 mortality rate with what was predicted. The SMR, shown in Table 2, is far higher than predicted in all regions, namely, the Khyber Pakhtunkhwa province, including the northern areas and the Federally Administered Tribal Territory (FATA). Table 2 displays the average annual values for $\mathrm{PM}_{10}$ corresponding to each region. Table 2 contains data pertaining to SMR for all areas of Pakistan. Along with COVID-19 reported cases, the area under consideration is graphically depicted in Fig. 1, while the SMR for all regions under examination is shown in Fig. 2.
Fig. 1 Number of confirmed COVID-19 cases by region of Pakistan as of 31 December 2020

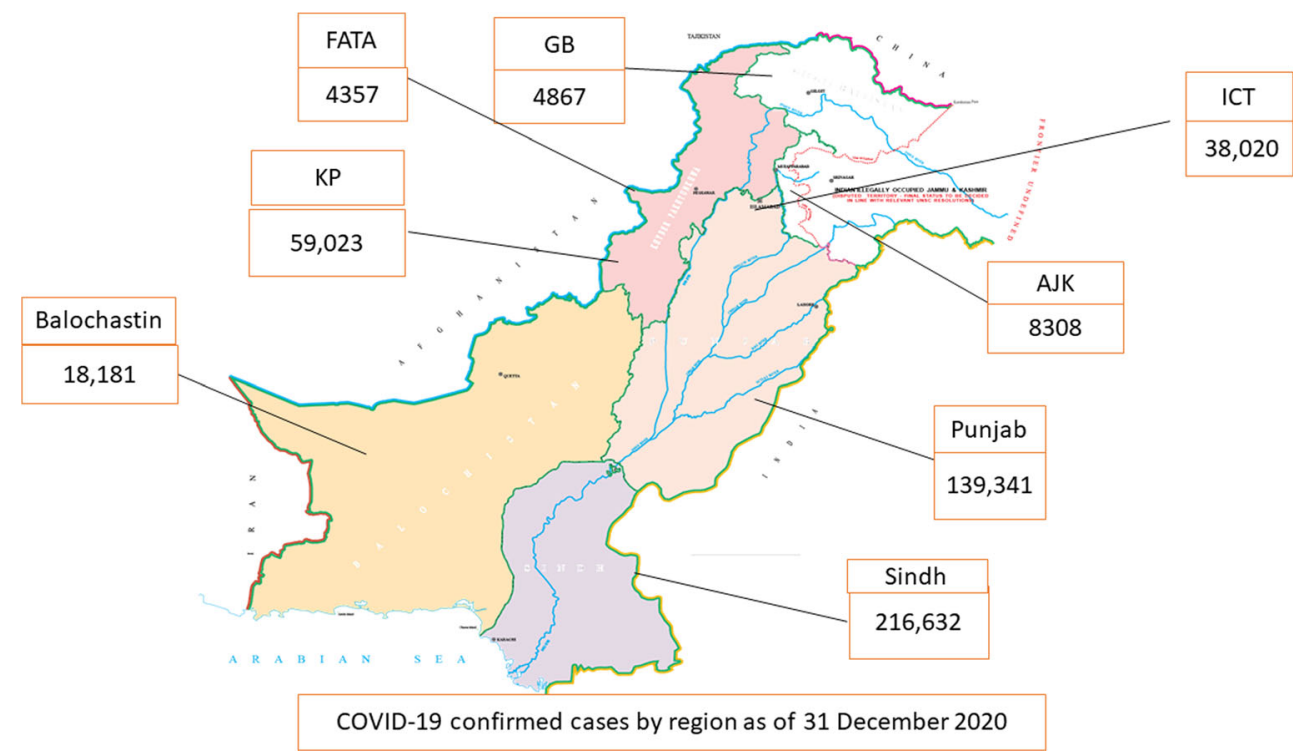




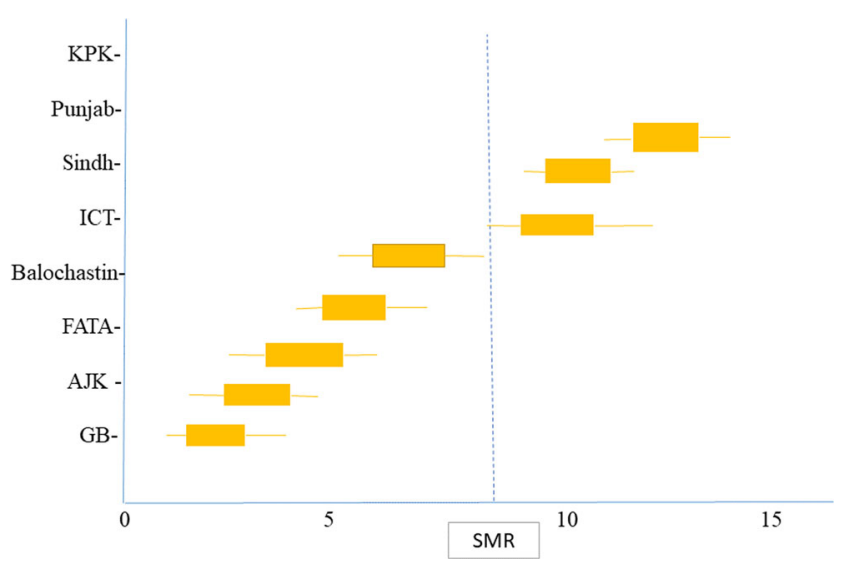

Fig. 2 Box plot displaying the SMR values. Whiskles represent the corresponding 95\% confidence intervals calculated for all provinces/ AJK and Federally Administrated Tribal Areas of Pakistan

\section{Dependence measure}

The coefficients of association among the ecological variables analyzed are exposed in Table 3. Study of regression between environmental variables (such as $\mathrm{NO}_{2}, \mathrm{PM}_{-10}, \mathrm{PM}_{2.5}$, bike paths, trees, soil, pedestrian areas, urban population, urban green spaces, motorcycles/cars, and bus/trucks), and the real mortality rate is given in Table 4. The existence of $\mathrm{PM}_{10}$ was separately correlated with the case status $(p=0.0011,95$ percent CI: $0.069,0.234)$. There was no important correlation with the other variables $(p>0.05)$ with case status. The interaction with the SMR is seen in Fig. 3 considering only the $\mathrm{PM}_{10}$ variables. In addition, Fig. 4 displays the country-wide scenario, separated by province with respect to SMR, thus highlighting the regional distribution with respect to $\mathrm{PM}_{10}$. Five groups were considered for the SMR distribution over the entire region of the Pakistan table. The two groups (below average and average) have lower than predicted mortality rates correlated with COVID-19. The intermediate class has a value about unity and is marginally higher than unity, thus indicating an estimated or slightly higher mortality rate, even as the extra two outlier have values where the mortality associated with COVID-19 is considerably higher than expected. The variety stands for the $\mathrm{WHO}$ and Pakistan particulate matter limits supported on a manifold of 10 (i.e., $20 \mu \mathrm{g} / \mathrm{mc}$ is the WHO boundary, while $68.3 \mu \mathrm{g} / \mathrm{m}^{3}$ is the Pakistan limit) in comparison to the $\mathrm{PM}_{10}$ map.

\section{Local spatial autocorrelation}

This study has been carried out following the recommendation of Anselin (1995) spatial autocorrelation analysis. Regression analysis was compared for comparative purposes, in regard to spatial autocorrelation. The conclusions of the study of spatial autocorrelation are summarized and presented in Fig. 5 and linked to the SMR and $\mathrm{PM}_{10}$ only. Following the recommendation of Murgante et al. (2020) and Dettori et al. (2021), Fig. 5 displays the effects of SMR and PM $_{-10}$ on the local predictor spatial autocorrelation. The result reveals very high-value clusters in the entire Khyber Pakhtunkhwa region and Southern Punjab region, correspondingly, through a positive degree of variation between the two distributions in the field narrowly considered Khyber Pakhtunkhwa.

\section{Experimental results and discussion}

The risk of mortality due to COVID-19 depends largely on the incidence of the disease and the rate of spread, and the main aspect is the human activity within the community. However, other variables could have a fun or a function in the promotion of this disease, such as hereditary issues (Frontera 2020; Zambrano-Monserrate et al. 2020; Vianello and Braccioni 2020) or ecological factors (Frontera 2020; ZambranoMonserrate et al. 2020; Vianello and Braccioni 2020)

Table 3 Interaction among environmental variables

\begin{tabular}{|c|c|c|c|c|c|c|c|c|c|c|}
\hline & $\mathrm{NO} 2$ & PM10 & PM2.5 & PA & $\mathrm{CP}$ & Soil & Trees & $\mathrm{MC}$ & BT & UGS \\
\hline $\mathrm{NO}_{2}$ & 1.0000 & & & & & & & & & \\
\hline $\mathrm{PM}_{10}$ & $0.4201 *$ & 1.0000 & & & & & & & & \\
\hline $\mathrm{PM}_{2.5}$ & $0.4718^{*}$ & $0.4983 *$ & 1.0000 & & & & & & & \\
\hline PA & 0.0643 & $0.2971 *$ & $0.3563^{* *}$ & 1.0000 & & & & & & \\
\hline $\mathrm{CP}$ & $0.4049 *$ & 0.4418 & $0.4251^{*}$ & 0.2783 & 1.0000 & & & & & \\
\hline Soil & $0.4849 *$ & 0.1746 & 0.2510 & 0.0347 & 0.2101 & 1.0000 & & & & \\
\hline Trees & 0.0868 & 0.3578 & 0.3231 & 0.0691 & $0.4202 * *$ & -0.1671 & 1.0000 & & & \\
\hline $\mathrm{MC}$ & 0.0417 & -0.2695 & -0.2737 & -0.0376 & -0.0741 & 0.3912 & -0.1051 & 1.0000 & & \\
\hline BT & -0.5910 & -0.3510 & -0.2415 & -0.4511 & -0.3973 & $-0.4400^{* *}$ & 0.0921 & 0.0190 & 1.0000 & \\
\hline UGS & 0.3475 & -0.0156 & 0.0614 & 0.1791 & -0.0167 & -0.0673 & 0.2085 & -0.1305 & 0.0706 & 1.0000 \\
\hline
\end{tabular}

“*” and “**” indicate significance at 5 and $1 \%$ 
Table 4 Multivariate regression analysis for environmental variables with respect to SMR

\begin{tabular}{lllll}
\hline Variables & Coefficient & $\begin{array}{l}t- \\
\text { statistics }\end{array}$ & $p$ values & $95 \% \mathrm{CI}$ \\
\hline Constant & 0.350 & 2.510 & 0.0000 & $(-0.101,0.701)$ \\
$\mathrm{NO}_{2}$ & 0.023 & 1.971 & 0.0170 & $(-0.036,0.046)$ \\
$\mathrm{PM}_{10}$ & 0.347 & 4.150 & 0.0011 & $(0.069,0.234)$ \\
$\mathrm{PM}_{2.5}$ & 0.184 & 3.110 & 0.0190 & $(-0.119,0.052)$ \\
$\mathrm{CP}$ & -0.003 & 0.978 & 0.3500 & $(-0.100,0.008)$ \\
$\mathrm{PA}$ & -0.374 & 0.783 & 0.3510 & $(-0.887,0.139)$ \\
Trees & 0.086 & 1.170 & 0.0860 & $(-0.019,0.035)$ \\
Soil & -0.101 & 1.961 & 0.1860 & $(-0.167,0.161)$ \\
UGS & -0.037 & 0.190 & 0.9750 & $(-0.005,0.007)$ \\
Motorcycles/Cars & -0.054 & 2.750 & 0.0025 & $(-0.038,0.186)$ \\
BT & 0.241 & 3.150 & 0.0070 & $(0.189,0.259)$ \\
\hline
\end{tabular}

(Mehmood et al. 2018; Waris et al. 2020; Anjum et al. 2020; Dettori et al. 2020). The subsistence of correlations amid air quality and COVID-19 humanity was first examined (Giangreco 2020; Setti et al. 2020a; Wu et al. 2020) with respect to air emissions from air pollutants such as (" $\mathrm{PM}_{10}$ " and " $\mathrm{PM}_{2.5}$ "). Nitrogen-dependent constituents and elements are produced from human activities. The core idea was the proliferation of air-related emissions would bring a strain on the health status of at-risk populations and establish requirements for the growth and complications of ventilator illness, which Dettori et al. (2021) in Po Valley, Italy, further implemented. In Pakistan, as of 31 December 2020, the current area-wise SMR in Table 2 indicates a higher mortality rate in Pakistan. An increase of 6.7 times more than predicted was considered to represent the collection of 8 regions in which KPK is one of the most polluted, with a value of 6.7. It can be shown that nearly all impacted regions of all regions are located in the KPK and are particularly characterized by a high average annual worth of $\mathrm{PM}_{-10}$. In the density groups, which typically contain between 238 and 268 individuals per quadrangle kilometer, a connection is also evident. The COVID-19 humanity analysis shows a very simple image between the area of KPK and the other regions included in these studies, with values a great deal senior than anticipated in the southern region and mortality standards consistent through those predictable in extra districts of Pakistan, especially in southern Punjab. Therefore, on the basis of recently published studies, a set of environmental variables was chosen to test the relationship with humanity due to COVID-19 in all regions of Pakistan. Keeping in brain that the major basis of air pollution may be similar, following the advice of Dettori et al. (2021), we performed a correlation study between the variables that cause air pollution in the field, and a few of these variables illustrated a very strong connection. In particular, the uppermost association coefficient between $\mathrm{PM}_{10}$ and $\mathrm{PM}_{2.5}$ was found to be equal to 0.8983 . Similarly, the correlation between $\mathrm{PM}_{10}$ and $\mathrm{NO}_{2}$ is 0.6201 . This is due to the fact that the particulate measurement schemes at this time in use revisit the average $\mathrm{PM}_{-10}$ attention, counting the $\mathrm{PM}_{2.5}$ portion. The two variables are, thus, closely connected. However, as the multiple-linear regression shows, among those variables that have been found to have a close relationship to the figure of deaths dispersed for every Pakistani region, artificial by COVID-19, $\mathrm{PM}_{-10}, \mathrm{PM}_{-2.5}$, and $\mathrm{NO}_{2}$ are among those variables that refute the results of Italy (Dettori et al. 2021). Pakistan was ranked number two in the world's air quality nations, which is why all air emissions tended to be statistically important for Pakistan. Since the variables $\mathrm{PM}_{10}, \mathrm{PM}_{2.5}$, and $\mathrm{NO}_{2}$ are statistically relevant, we consider $\mathrm{PM}_{10}$ as an important risk stratification factor in this analysis because $\mathrm{PM}_{10}$ did not decrease significantly during the lockdown, which is why $\mathrm{PM}_{10}$ was considered an independent mortality predictor for COVID-19 and early epidemic recurrence pointer as indicated by Setti et al. (2020a) and Dettori et al. (2021).
Fig. 3 Relationship between SMR and $\mathrm{PM}_{10}$. Red circles represent Khyber Pakhtunkhwa region. Further, it is to be noted that the size of the circle has no meanings

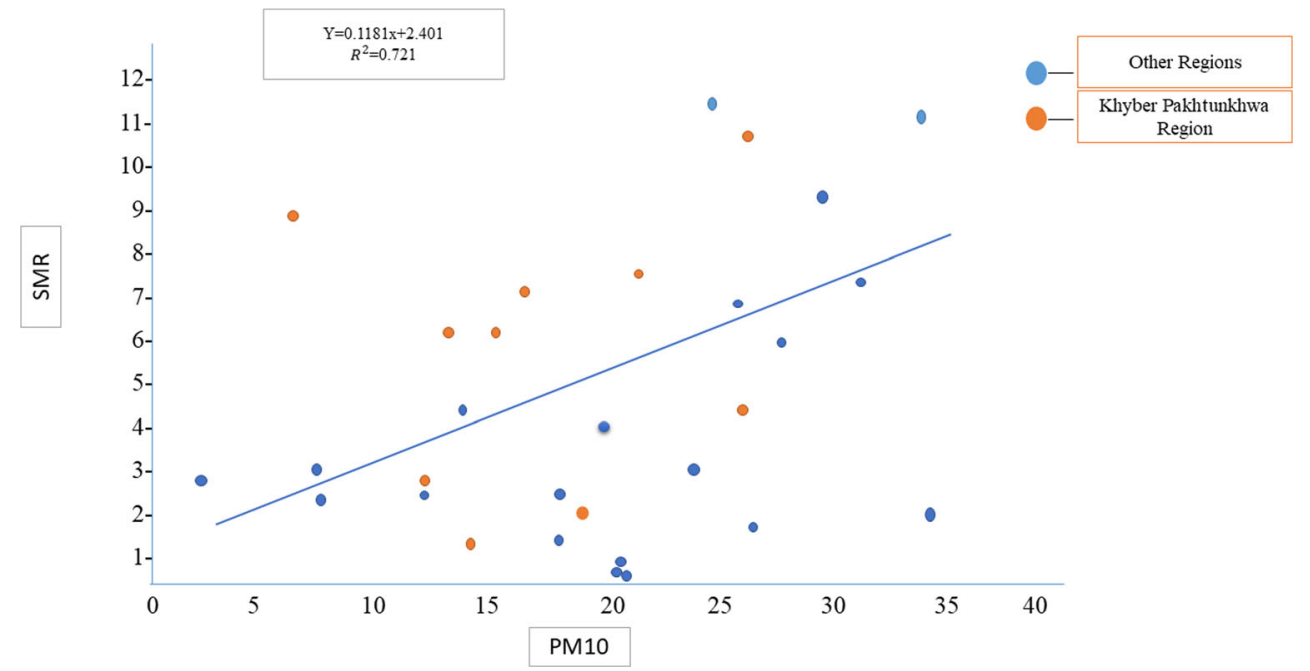




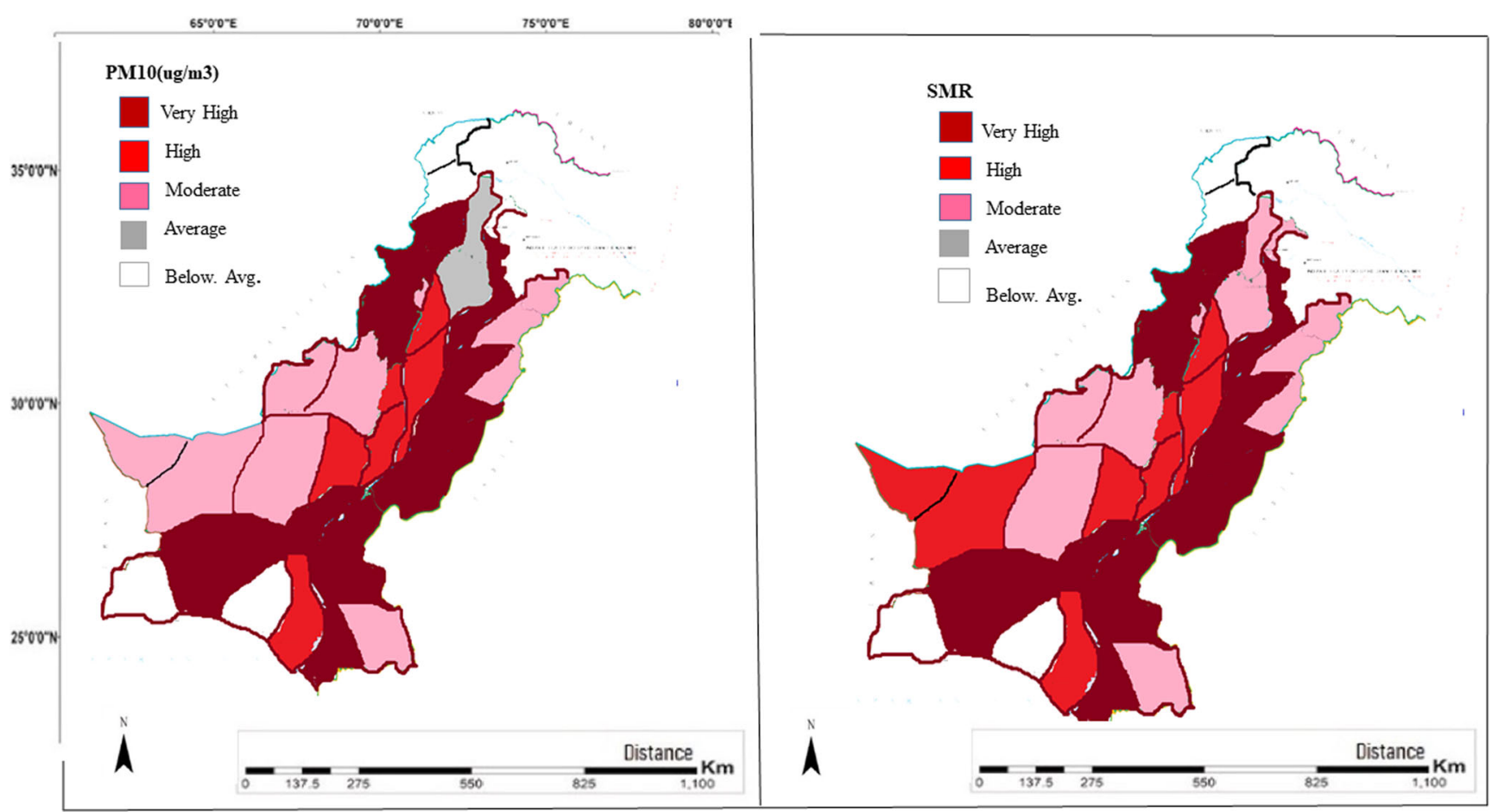

Fig. $4 \mathrm{PM}_{10}$ level per/provinces and specific mortality rate per province in Pakistan

In addition, certain spatial autocorrelation with respect to $\mathrm{PM}_{10}$ and SMR can be observed, indicating a certain degree of similarities between the COVID-19 regions most affected in Pakistan and the highest reported $\mathrm{PM}_{10}$ values. Many studies hypothesize a link between the prevalence of air contaminants and humanity. In addition to a current methodical

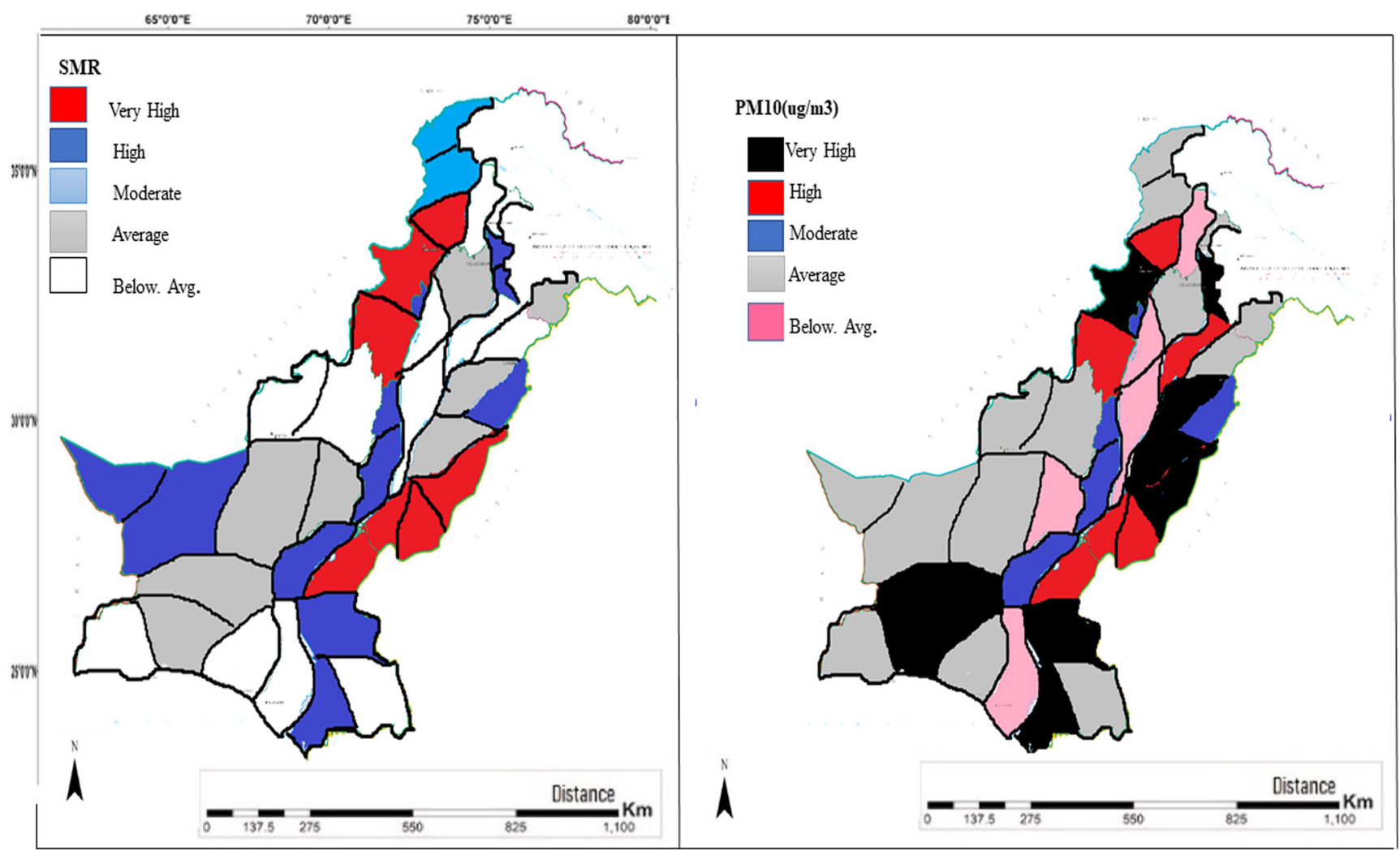

Fig. 5 Graphical representation of local indicators of spatial autocorrelation in connection with SMR and $\mathrm{PM}_{10}$ 
literature review (Zambrano-Monserrate et al. 2020; Copat et al. 2020; Dettori et al. 2021), which highlights the significant contribution of $\mathrm{PM}_{-10}, \mathrm{PM}_{-2.5}$, and $\mathrm{NO}_{2}$ activates for the increase and lethality of COVID-19 in Italy, Xiao Wu (2020) identified in his research that a slight increase in long-term exposure to $\mathrm{PM}_{-2.5}$ leads to a strong ink Similarly, in his report, Shi et al. (2020) identified the role of temperature in the dynamics of the outbreak of COVID-19 in China. In any event, these are observational studies, so it would be important for further evaluation to be carried out, especially from an etiological point of view (Setti et al. 2020b; Anjum et al. 2020). There is a superior necessity to carry out parallel research in emerging countries in Asia and Africa, where air pollution is at an extreme degree, and to equate the findings with a study established in developed countries to further improve the investigation. Furthermore, what has therefore appeared is that a deep resemblance is needed in the control of air pollution, in the scrupulous of the $\mathrm{PM}_{-10}$, which did not diminish dramatically throughout the lockdown. In this information, the efficacy of the steps adopted at the local level to mitigate air emissions can be checked by monitoring. In addition, because of the sensitivity of environmental threats, the pandemic could provide an incentive to contrast group aggression (Carducci et al. 2019; Dettori et al. 2021; Anjum et al. 2020).

\section{Conclusion and policy implications}

Regarding ambient emissions and both the dissemination of the virus in the development of eruptions and the rate of container casualty, this investigation tends to establish rudiments to support the presence of a correlation among air effluence, referred to as $\mathrm{PM}_{10}$ particulate matter and COVID-19 death. In 2020, some impressive circumstances could have worsened the environmental situation throughout Pakistan, especially in the area of KPK, making Pakistan a prominent country in South Asia. The spatial allocation of SMR-related COVID19 deaths shows correlations in the spatial models tried, particularly with particles, as shown by multivariate regression. Our findings on air quality and the risk of corona virus mortality are in line with the findings of Dettori et al. (2021), Ma et al. (2020), and Xiao Wu (2020). Conceptually, our study results are the same as those previously done for the USA (Xiao Wu 2020), for China (Ma et al. 2020), and for Italy (Dettori et al. 2021) but differ in the point table as all air pollutants seem to be significant. Pakistan is an emerging Asian economy where the indices of air quality are high to the extent of risk. Pakistan is second among the dirty countries in the world, according to WHO (2020). Because of this, all air pollutant variables such as $\mathrm{NO}_{2}, \mathrm{PM}_{2.5}$, and $\mathrm{PM}_{10}$ tend to be statistically important and play a significant role in the likelihood of COVID-19 mortality. In Pakistan, there are solid reasons for considering $\mathrm{PM}_{10}$ as an independent air quality measure. The only air pollution indicator on which the data can be available. Second, $\mathrm{PM}_{10}$ has a good association with $\mathrm{NO}_{2}$ and $\mathrm{PM}_{2.5}$ to compare the findings with those obtained for advanced countries where air quality is at normal levels.

\section{Policy implementations}

With respect to policy recommendations, we should reinforce the need to proceed in support of measures aimed at reducing atmospheric emissions by speeding up current plans and initiatives addressing all sources of ambient pollution: industry, domestic heating, and transport. While Pakistan is in the right direction with respect to reducing the country's air pollution, it will take time to normalize the extent of the serious danger of air pollution. The sitting government is highly worried about the climate. In this regard, in his first term of power in Khyber Pakhtunkhwa, the new Prime Minister launched the Billion Tree Planning Project (BTPP). While in his current term, the BTP project has been upgraded to 10 billion nationally. Imran Khan, Pakistan's prime minister, made the nation realize that the sitting government made legal regulations on air quality in the country without a sound atmosphere and barred all illegal brick manufacturing factories for this reason. Indeed, these actions taken by Pakistan's government would help the environment and reduce air pollution in the long term. Additionally, there is a greater need for investment in safe and green transport, and green building technologies should also be increased, beginning even with rapidly relevant steps, i.e., road cleaning, pollution-eating paints, façades and plants, paying special attention to housing sanitary facilities.

\section{Future research work}

Exploration of this research work uncover many research questions. We are going to explain some of them here. First, there is a greater potential to replicate similar research work in Europe and Africa to investigate the risk of mortality and the spread of COVID-19 and compare the results with the one obtained from this study. Second, age and season variation are very influential variables playing an important role in the spread of COVID-19 and its updated version. One may consider it as point of future research work. Apart from this, there is a greater need to investigate the effectiveness of corona virus vaccine and its classification. Additionally, techniques for optimum allocation of corona virus vaccine in a short span of time are also the need of the present situation.

Abbreviations COVID-19, Corona virus; CP, Cycle paths; PA, Pedestrianized road surface ( $\mathrm{m}^{2} /$ inhabitant); UGS, Urban green spaces; Moto, Motorcycles; SMR, Specific mortality rate; BT, Heavy buses and trucks; FATA, Federal Administrated Tribal Area; $\mathrm{NO}_{2}$, Nitrogen dioxide (average yearly value $(\mu \mathrm{g} / \mathrm{mc})$ ) $; \mathrm{PM}_{2.5}$, Particulate matter $\leq 2.5 \mu \mathrm{m}$ 
(average yearly value $(\mu \mathrm{g} / \mathrm{mc})$ ); $\mathrm{PM}_{10}$, Particulate matter $\leq 10 \mu \mathrm{m}$ (average yearly value $(\mu \mathrm{g} / \mathrm{mc}))$; WHO, World Health Organization; LISA, Local indicator spatial autocorrelation; BTP, Billion Tree Plantation Program

\section{Author contribution NA.}

Funding This research was financially supported by the Provincial Government of Khyber Pakhtunkhwa, Pakistan, under Grant. No. KP/ HE/2020/1171901.

Data availability The data used in this analysis were extracted from numerous sources. Data related to COVID-19, such as a number of confirmed cases, deaths, active cases, and area recoveries, was collected from the Ministry of National Health Services (MNHS 2020) available online at http://www.covid.gov.pk. Real-time air quality monitoring project (AQICN 2020) available at https://aqicn.org/country/pakistan/, Ministry of Environment, Government of Pakistan available at http://www. adaptation-undp.org., and air pollution data were collected from Pakistan Ministry of Climate Change available at http://www.mocc.gov. pk. All the results reported in this research were carried out in Rcomputational environment.

\section{Declarations}

Ethics approval and consent to participate This article does not contain any studies with human applicants or animals accomplished by any of the authors.

Competing interests The authors declare no competing interests.

Consent for publication NA.

\section{References}

Anjum MS, Ali SM, Subhani MA, Anwar MN, Nizami AS, Ashraf U, Khokhar MF (2020) An emerged challenge of air pollution and ever-increasing particulate matter in Pakistan; a critical review. J Hazard Mater 123943

Anselin L (1995) Local indicators of spatial association-LISA. Geogr Anal 27:93-115

AQICN (2020) Retrieved from air pollution in Pakistan real-time air quality monitoring project. https://aqien.org/country/pakistan/. Accessed 6 Jan 2021

Carducci AL, Fiore M, Azara A, Bonaccorsi G, Bortoletto M, Caggiano G, Calamusa A, De Donno A, De Giglio O, Dettori M et al (2019) Environment and health: risk perception and its determinants among Italian university students. Sci Total Environ 691:1162-1172

Copat C, Cristaldi A, Fiore M, Grasso A, Zuccarello P, Signorelli SS, Conti GO, Ferrante M (2020) The role of air pollution (PM and NO2) in COVID-19 spread and lethality: a systematic review. Environ Res 191:110129. https://doi.org/10.1016/j.envres.2020. 110129

Dettori M, Deiana G, Balletto G, Borruso G, Murgante B, Arghittu A, Castiglia P (2021) Air pollutants and risk of death due to COVID-19 in Italy. Environ Res 192:110459

Dettori M, Pittaluga P, Busonera G, Gugliotta C, Azara A, Piana A, Arghittu A, Castiglia P (2020) Environmental risks perception among citizens living near industrial plants: a cross-sectional study. Int J Environ Res Public Health 17:4870

D'alessandro D, Gola M, Appolloni L, Dettori M, Fara GM, Rebecchi A, Capolongo S (2020) COVID-19 and living space challenge. Well-being and public health recommendations for a healthy, safe, and sustainable housing. Acta Bio Medica: Atenei Parmensis 91(9-S):61.

Frontera AM (2020) Regional air pollution persistence links to COVID19 infection zoning. J Infect 81:318-356. https://doi.org/10.1016/j. jinf.2020.03.045

Giangreco G (2020). Case fatality rate analysis of Italian COVID-19 outbreak. J Med Virol 92(7):919-923

Ghorani-Azam A, Riahi-Zanjani B, Balali-Mood M (2016). Effects of air pollution on human health and practical measures for prevention in Iran. Journal of research in medical sciences: the official journal of Isfahan University of Medical Sciences 21.

ISPRA (2016) XIV Rapporto Qualit'a dell'ambiente urbano. Edizione 2018. Stato dell'Ambiente 82/2018. Available online: https:// www.isprambiente.gov.it/it/pubblicazioni/stato-dellambiente/xivrapporto-qualita-dell2019ambiente-urbano-edizione-2018. Accessed 3 Oct 2020

Lai AL, Millet JK, Daniel S, Freed JH, Whittaker GR (2020) Coronavirus disease 2019 (COVID-19): current status and future perspectives. Lancet 395(April): 1315

Ma Y, Zhao Y, Liu J, He X, Wang B, Fu S, Yan J, Niu J, Zhou J, Luo B (2020) Effects of temperature variation and humidity on the death of COVID-19 in Wuhan, China. Sci Total Environ 724:138226. https://doi.org/10.1016/j.scitotenv.2020.138226

Mazhar M, Abid I, Hussain S, Shahzad N (2020) The effects of regional climatic condition on the spread of COVID-19 at global scale. Sci Total Environ 739. https://doi.org/10.1016/j.scitotenv.2020.140101 https://www.sciencedirect.com/science/article/pii/ S0048969720336214

Mehmood T, Tianle Z, Ahmad I, Li X, Shen F, Akram W, Dong L (2018) Variations of PM2.5, PM10 mass concentration and health assessment in Islamabad, Pakistan. IOP Conf Ser Earth Environ Sci 133(1). https://doi.org/10.1088/1755-1315/133/1/012031

Ministry of Climate Change, Government of Pakistan (2020) http://www. mocc.gov.pk/

MNHS (2020) Retrieved from COVID-19 health advisory platform by Ministry of National Health Services Regulations and Coordination. http://covid.gov.pk/. Accessed 15 Jan 2021

Murgante B, Balletto G, Borruso G, Las Casas G, Castiglia P, Dettori M (2020) Geographical analyses of COVID-19's spreading contagion in the challenge of global health risks. TEMA J Land Use Mobil Environ:283-304

Pakistan Statistics Division (2020) https://www.pbs.gov.pk

Pakistan Bureau of Statistics(2020) avaliable at: https://www.pbs.gov.pk

Peng L, Zhao X, Tao Y, Mi S, Huang J, Zhang Q (2020) The effects of air pollution and meteorological factors on measles cases in Lanzhou, China. Environ Sci Pollut Res 27:13524-13533

Setti L, Passarini F, De Gennaro G et al (2020a) Potential role of particulate matter in the spreading of COVID-19 in Northern Italy: first observational study based on initial epidemic diffusion. BMJ Open 10:e039338. https://doi.org/10.1136/bmjopen-2020-039338

Setti L, Passarini F, De Gennaro G, Barbieri P, Pallavicini A, Ruscio M, Piscitelli P, Colao A, Miani A (2020b) Searching for SARS-COV-2 on particulate matter : a possible early indicator of COVID-19 epidemic recurrence. Int J Environ Res Public Health 17:2986. https:// doi.org/10.3390/ijerph17092986

Shi P, Dong Y, Yan H, Zhao C, Li X, Liu W, He M, Tang S, Xi S (2020) Impact of temperature on the dynamics of the COVID-19 outbreak in China. Sci Total Environ 728(77):138890. https://doi.org/10. 1016/j.scitotenv.2020.138890

Vandenbroucke JP (1982) A shortcut method for calculating the 95 percent confidence interval of the standardized mortality ratio. Am J Epidemiol 115:303-304

Vianello A, Braccioni F (2020) Geographical overlap between alpha-1 antitrypsin deficiency and COVID-19 infection in Italy: casual or causal? Archivos de bronconeumologia 56(9):609 
Waris A, Atta UK, Ali M, Asmat A, Baset A (2020) COVID-19 outbreak: current scenario of Pakistan. New Microbes New Infect 35(20): 100681. https://doi.org/10.1016/j.nmni.2020.100681

WHO Timeline (2020) Retrieved from world health organization. https:// www.who.int/news-room/detail/27-04-2020-who-timeline - covid19. Accessed 15 Jan 2021

World Health Organization (2016) Air quality guidelines for particulate matter, ozone, nitrogen dioxide and sulfur dioxide. Available online: https://apps.who.int/iris/bitstream/handle/10665/69477/.WHO SDE PHE_OEH_06.02_eng.pdf? sequence $=1$. Accessed 2 Oct 2020

World Health Organization (2017) Air pollution. Available online: https://www.who.int/health-topics/air-pollution\#tab=tab_1. Accessed 3 Oct 2020

Wu C, Chen X, Cai Y, Zhou X, Xu S, Huang H, Song Y (2020) Risk factors associated with acute respiratory distress syndrome and death in patients with coronavirus disease 2019 pneumonia in Wuhan, China. JAMA Intern Med 180(7): 934-943

Xiao Wu RC (2020) Harvard University. Retrieved from COVID-19 PM2.5 Exposure to air pollution and COVID-19 mortality in the United States: a nationwide. https://projects.iq.harvard.edu/covid$\mathrm{pm}$

Zambrano-Monserrate MA, Ruano MA, Sanchez-Alcalde L (2020) Indirect effects of COVID-19 on the environment. Sci Total Environ 728:138813. https://doi.org/10.1016/j.scitotenv.2020. 138813

Publisher's note Springer Nature remains neutral with regard to jurisdictional claims in published maps and institutional affiliations. 